\title{
PAIDEIA E ASCENSÃO SOCIAL NA ÁFRICA ROMANA: A BIOGRAFIA DE APULEIO DE MADAURA (SÉC. II D.C.)
}

Belchior Monteiro Lima Neto ${ }^{1}$

\begin{abstract}
Resumo
Com o retorno dos estudos biográficos, verificado nas últimas décadas, abrem-se novas possibilidades de pesquisa no tocante à Antiguidade, demonstrando-nos a complexidade da ação dos indivíduos nas sociedades antigas. Dentro desta perspectiva, como objeto de investigação, analisaremos a história de vida de Apuleio de Madaura, com o intuito de perceber a importância da paideia greco-romana como elemento fulcral no processo de inserção social das elites norte-africanas na sociedade romana imperial. Em termos gerais, a biografia de Apuleio pode ser compreendida como um caso modelo no seio das aristocracias citadinas locais, oferecendo-nos uma amostra do modo como este grupo, por meio da instrução na paideia, ascendia socialmente e se apropriava das novas possibilidades abertas pelo advento do domínio romano na região.
\end{abstract}

\section{Palavras-chave}

Império Romano; África Proconsular; biografia; Apuleio de Madaura; paideia.

\begin{abstract}
The comeback of biographical studies in the last decades opens new possibilities of research in what concerns Ancient History. That shows how complex the action of individuals in ancient societies was. Within this perspective, our investigation will focus on the life of Apuleius from Madauros, in order to perceive the importance of Greek-Roman paideia as a fundamental element of social insertion for North-African elites in Roman imperial society. In general terms, the biography of Apuleius could be understood as a model case in the heart of local urban aristocracies, offering us an example of the way in which this group, through the instruction in paideia, experienced social ascension and grasp the new possibilities opened by the advent of Roman domination in that region.
\end{abstract}

\footnotetext{
${ }^{1}$ Professor Doutor - Universidade Federal do Espírito Santo, Vitória, Brasil. E-mail: belchior67@hotmail.com
} 


\section{Keywords}

Roman empire; Proconsular Africa; biography; Apuleius from Madauros; paideia.

\section{Introdução}

A historiografia experimentou, nas últimas décadas, uma série de retornos. Os pesquisadores voltaram os olhos, mais uma vez, para a História Política, para o acontecimento, e perceberam as relações intrínsecas da história com a narrativa. ${ }^{2} \mathrm{O}$ retorno da biografia ao escopo de interesse dos historiadores se relaciona a um período de incertezas, de crise epistemológica enfrentada pela disciplina a partir de finais dos anos 1960. A biografia, que ora emerge, não mais se preocupa com a narrativa de vida dos homens "predestinados" aos grandes atos históricos, principalmente identificados com a História Política e Militar. As possibilidades atuais apontam para uma análise da vida das personagens, relacionada ao contexto de sua existência. Um contexto que, longe de ser determinante sobre as ações e os atos humanos, se torna um elemento por meio do qual os indivíduos constroem o seu mundo, fazem as suas escolhas e agem em prol dos seus interesses (Loriga, 2011: 211-231). Nas palavras de Chartier (1994: 98): houve uma virada epistemológica da história em direção ao indivíduo, desviando-se o olhar "das regras impostas para as suas aplicações".

Mediante esta nova perspectiva acerca dos estudos biográficos, tomaremos como objeto de investigação a história de vida de Apuleio de Madaura, com o intuito de perceber a importância da paideia greco-romana como um elemento de distinção e de prestígio, compreendendo-a como um meio privilegiado de ascensão social. Acreditamos que a paideia, por constituir um conjunto de aprendizados literários, retóricos, oratórios, políticos, filosóficos e mitológicos fundados nos princípios da cultura clássica greco-romana, tornava-se um componente indispensável para a obtenção de uma posição de destaque na sociedade imperial. Em termos gerais, percebemos os fatos transcorridos na vida de Apuleio como um caso modelo no seio das elites citadinas no norte da África, oferecendo-nos uma amostra do modo como as aristocracias municipais das diversas cidades norte-africanas, por meio da instrução na paideia, se inseriam na sociedade imperial e se apropriavam das novas possibilidades abertas pelo advento do domínio romano na região.

\footnotetext{
${ }^{2}$ Uma problematização pormenorizada sobre as questões que associam a historiografia atual com o acontecimento, a narrativa e a história política pode ser vista em autores como René Rémond (2003), Roger Chartier (1994), Paul Ricoeur (1997) e Michel de Certeau (1982).
} 


\section{Apuleius Madaurensis}

Em relação a Apuleio, há muitas controvérsias sobre os seus dados biográficos, assim como acontece com a maioria dos autores da Antiguidade. Assim, o que se considera como biografia do autor resulta de uma compilação de dados extraídos de minuciosos exames dos documentos, com indícios que se alteram a partir de informações novas, variando da simples suposição a traços evidentes, sendo que o próprio Apuleio inclui muitos elementos autobiográficos em suas obras, principalmente em três delas, Apologia, Florida e Metamorphoses. ${ }^{3}$

Apuleio provavelmente nasceu na década de 120, na África do Norte, e viveu sob os governos de Adriano (117-138), Antonino Pio (138-161) e Marco Aurélio (161-180). A data de seu nascimento pode ser inferida a partir de algumas passagens de suas obras. Em Florida (XVI, 36-37), Apuleio reivindica ser companheiro de estudos do ex-cônsul Emiliano Estrabão, do que se pode supor terem idades aproximadas. Como na época de seu consulado, em 156, Estrabão tinha aproximadamente 32 anos, isso nos faz concluir que ambos teriam nascido na terceira década do século II (Harrison, 2000: 3). ${ }^{4}$ Além disso, também colabora para tal datação o fato de que, em Apologia (89, 5-6), Apuleio declara ser um pouco mais jovem do que a sua esposa, Emília Pudentila, a quem é atribuída a idade de 40 anos. Como o julgamento que inspirou a composição de Apologia ocorreu em $159,{ }^{5}$ tal cronologia leva a supor que o autor deveria possuir pouco mais de 30 anos à época.

A cidade natal de Apuleio, ao que tudo indica, era Madaura, ${ }^{6}$ colônia romana fundada na Numídia por veteranos do exército no período Flaviano (69-96), o

\footnotetext{
${ }^{3}$ Em relação às obras escritas por Apuleio, há uma variedade ampla de estilos. Encontram-se discursos, textos filosóficos, poesias, novelas latinas, hinos, panegíricos, tratados de botânica, zoologia, medicina, astrologia, entre outros. Em suma, Apuleio era um autor polivalente e versado em diferentes gêneros literários, escrevendo tanto em grego quanto em latim. Da vasta produção do autor, chegaram à contemporaneidade apenas 6 obras: uma novela latina (Metamorphoses), três tratados filosóficos (De Platone, De Mundo e De Deo Socratis), um discurso jurídico (Apologia) e uma antologia de discursos laudatórios (Florida).

${ }^{4}$ Em Florida (XVI, 40), Apuleio se refere a Aemilianus Strabo como vir consularis. De acordo com Corpus Inscriptionum Latinarum (VI, 2067; 2086), Estrabão foi cônsul, em Roma, no ano de 156.

5 A data do julgamento de Apuleio, em Sabrata, pode ser estabelecida por intermédio do cruzamento de dados provenientes de Apologia $(94,5)$ com três inscrições epigráficas encontradas no teatro da cidade de Lepcis (Inscriptions of Roman Triplitania, 533; 534; 535), que atestam o proconsulado de Loliano Avito em 157/158. Como Apuleio foi julgado por Cláudio Máximo, sucessor de Avito no governo de África, acreditamos que o julgamento do autor madaurense tenha ocorrido no ano de 159 (Guey, 1951: 308).

${ }^{6}$ Madaura é hoje a moderna Mdaurush, na Argélia.
} 
que se deduz de uma inscrição epigráfica local que a designa como Colonia Flavia Augusta veteranorum Madaurensium (Inscriptions Latines de l'Algérie, 2152). À época de Apuleio, Madaura era uma cidade de pequenas proporções, situada a 230 quilômetros a oeste de Cartago e a 900 metros acima do nível do mar, no declive sul da cadeia do Atlas, fazendo fronteira com algumas das tribos seminômades que habitavam o sul da Numídia, principalmente os Gétulos e os Musulanes (Harrison, 2000: 4). ${ }^{7}$ O próprio Apuleio, em Apologia (24, 1-10), descreve a sua pátria de origem "situada en la frontera misma de Numidia y Getulia" e a si próprio como "seminúmida e semigétulo". Corroborando essa última informação, pode-se citar também dois marcos divisórios inscritos em pedra encontrados nos limites da cidade de Madaura, indicando ser o local uma região limítrofe entre os madaurenses e os musulanii (I.L.ALG., 2828; 2829).

A determinação de Madaura como o lugar de nascimento de Apuleio é oferecida por algumas citações feitas pelo autor e por demais fontes suplementares. Em Apologia $(24,8-9)$, Apuleio descreve a sua terra natal como uma colônia romana fundada por veteranos ao sul da Numídia, localização que corresponde à região onde se assentava a Colonia Madaurensium. Além disso, atribuindo-se às Metamorphoses um viés autobiográfico, no qual o protagonista da obra, o grego Lúcio, representaria uma espécie de alter-ego do próprio Apuleio, pode-se compreender a afirmação de que a personagem Lúcio era madaurense com uma indicação de que Apuleio, na realidade, declara-se como proveniente da cidade de Madaura (Metamorphoses, XI, 27).

Essa designação, ademais, é corroborada pela descoberta do pedestal de uma estátua com um fragmento de dedicatória dos cidadãos de Madaura a um filósofo platônico que era motivo de orgulho para a sua cidade, cujo texto afirma: "os cidadãos de Madaura dedicaram às expensas públicas esta estátua ao filósofo platônico que constitui para eles honra" (I.L.ALG., 2115). ${ }^{8}$ Mesmo que não se possa atribuir, com certeza, a estátua a Apuleio, ao fazer alusão a um filósofo da escola platônica e por não existir nenhuma informação acerca de outro filósofo dessa região que tenha tido destaque, a estátua foi, ao que tudo leva a crer, erguida em homenagem a Apuleio, conhecido na Antiguidade como philosophus platonicus Madaurensis (Gaisser, 2008: 29-36). ${ }^{9}$

\footnotetext{
7 Muitos autores, tais como Mahjoubi (1985), Raven (1993) e Chausa (1994), destacam a importância que essas colônias de veteranos tiveram no intuito de reforçar a vigilância das fronteiras e de controlar as possíveis ações beligerantes das tribos seminômades próximas.

8 Tradução do latim elaborada pelo autor.

9 A designação de Madaura como cidade natal de Apuleio também foi indicada por Agostinho de Hipona (De civitate Dei, 8, 14; Epistolae, 102, 32), que o denominava, no início do século V, Philosophus platonicus madaurensis.
} 
A família de Apuleio, segundo dados apresentados pelo próprio autor, pertencia à oligarquia municipal norte-africana, isto é, ao ordo decurionum da cidade de Madaura. Em Apologia (24, 8-9), Apuleio declarou que seu pai alcançou a mais alta magistratura municipal - ou seja, o cargo de duunvir $-{ }^{10}$ deixando aos filhos uma herança de dois milhões de sestércios, quantidade suficiente para ostentarem um status social elevado. ${ }^{11}$ Por meio da epigrafia remanescente de Madaura, constatamos que a família dos Apuleii era uma das mais importantes na colônia. O fato de gravarem em pedra seus epitáfios, como sugere José d'Encarnação (2010: 109-120), indica uma posição social elevada e a existência de antepassados importantes o suficiente para serem lembrados e enaltecidos pelos demais cidadãos, como foram os casos de C. Apuleius Rogatus, Apuleius Rufus, Apuleia Quarta e Apuleius Datianus Ponponianus, provavelmente indivíduos com algum grau de parentesco com Apuleio e membros destacados da sociedade madaurense (I.L.ALG., 2276; 2277; 2278; 2279; 2236). ${ }^{12}$

No tocante à paideia de Apuleio, ${ }^{13}$ ao que tudo indica, ele teria iniciado a sua formação educacional ainda na cidade de Madaura, dedicando-se às disciplinas do ensino elementar greco-romano: aritmética, leitura e escrita (Harrison, 2000: 5). Mesmo não dispondo de nenhuma informação consistente acerca desse período inicial da vida de Apuleio, é possível que ele, como um jovem pertencente às ordens superiores da sociedade provincial romana, tivesse a sua formação primeira na escola do litterator, para onde eram encaminhados, a partir dos sete anos de idade, os filhos dos membros das elites citadinas locais (Marrou, 1956: 265-266).

Entre os 11 e os 12 anos, pode-se conjeturar, Apuleio, como de costume para aqueles que poderiam pagar por uma educação mais refinada, teria sido enviado à escola do grammaticus, o segundo nível da escolarização romana. Nessa etapa, os estudantes aprendiam noções de retórica, eloquência e literatura clássica, conjugadas com lições de mitologia, conhecimentos fundamentais para seu futuro como homem público e cidadão (Opeku, 1993: 33). Com tal

${ }^{10}$ Os duunviri eram os mais importantes magistrados de uma civitas romana, sendo eleitos anualmente como os responsáveis pela condução da cidade (Alföldy, 1996: 177).

${ }^{11}$ Em muitas cidades grandes ou médias, como Cartago, no norte da África, ou Como, na Itália do norte, o censo mínimo necessário ao decurionato era de cem mil sestércios, evidência que demonstra quão opulenta era a herança recebida por Apuleio (Alföldy, 1996: 175).

12 A família dos Apuleii também é atestada pela epigrafia em outra cidade númida, próxima a Madaura, Theveste, fato que sugere uma posição de destaque da gens Apuleii na região (I.L.ALG., 3178; 3179; 3601; 3608).

${ }^{13}$ Utiliza-se o termo paideia no sentido de uma "formação educacional fundada nos princípios da cultura clássica que tinha por finalidade incutir no homem o autocontrole, o decorum e o gosto pelo belo" (Silva, 2010: 8). 
finalidade, Apuleio teve de deixar Madaura e se mudar para um centro de maior projeção: Cartago. Tais dados são apresentados por Apuleio, em Florida (XVIII, 15), quando o autor declara que sua "mi niñez ha transcurrido entre vosostros, vosotros mismos habéis sido mis maestros; mi doctrina filosófica, aunque madurada em Atenas, en el Ática, ha nacido, sin embargo, aqui [em Cartago]". Mais adiante, Apuleio (Flor., XVIII, 36) complementa: “la recompensa que yo, Cartagineses, os pago en todos los lugares del mundo, a cambio de las enseñanzas que he aprendido de vosostros en mi niñez, [...] [é me apresentar] como un discípulo de vuestra ciudad"

Após anos de estudos em Cartago, Apuleio deu continuidade à sua formação educacional em um centro mais prestigioso e cosmopolita: Atenas. Como de costume, entre as elites romanas, por volta dos 15 anos, aqueles cuja família dispusesse de recursos suficientes poderiam adentrar na escola do rhetor, onde teriam a oportunidade de aprofundar os seus conhecimentos em gramática, retórica, dialética, aritmética, geometria, música, astronomia e filosofia (Silva, 2010: 8). Teria sido em Atenas, portanto, que Apuleio completou a sua formação político-cultural, como ele mesmo indica:

La primera copa, la que nos brinda el maestro de escuela, nos saca de la ignorancia; la segunda, la del gramático, nos provee de conocimentos; la tercera, la del rétor, nos proporciona las armas de la elocuencia. La mayoría se contenta con beber hasta este limite. Yo he apurado además otras copas en Atenas: la de la Geometría, de límpida transparencia; la de la Música, llena de dulzura; la de la Dialéctica, un tanto austera; $y$, sobre todo, la de la Filosofía universal, rebosante siempre de inagotable néctar (Apul., Flor., XX, 2-4).

Ainda em Atenas, Apuleio se interessou pela filosofia de Aristóteles e, principalmente, pela de Platão, como se depreende dos dois tratados filosóficos que posteriormente escreveu: De Mundo, uma síntese da cosmologia de Aristóteles; e De Platone, um resumo da vida e dos ensinamentos de Platão. Em Atenas, ademais, Apuleio teria dado vazão aos seus interesses em questões relacionadas às religiões de mistério, como se observa na seguinte passagem de sua Apologia (55, 8): “he tomado parte, en Grecia, [...] de la mayor parte de los cultos mistéricos. Conservo aún, com sumo cariño, ciertos símbolos y recuerdos de tales cultos"

Após completar sua formação educacional em Atenas, Apuleio provavelmente se dirigiu a Roma. ${ }^{14} \mathrm{Na}$ Capital do Império, o autor teria tentado a carreira

${ }_{14}$ Provavelmente antes de seguir para Roma, Apuleio teria viajado pela Ásia Menor e conhecido as regiões de Samos e Frígia, como se depreende por meio dos excertos presentes em Florida (XV) e De Mundo (326-329). 
de advogado, o que se supõe por intermédio da associação entre sua biografia e a do protagonista de Metamorphoses (XI, 26; XI, 30). Segundo conjeturas de Coarelli (1989), a estadia de Apuleio em Roma teria ocorrido no final da década de 140 e proporcionaria ao autor madaurense a possibilidade da constituição de uma rede de relações de amizade com membros distintos da elite senatorial romana, fato corroborado por uma passagem de Florida (XVII, 4), na qual Apuleio afirma:

[...] tu mismo [Cipião Órfito, então governador da África Pronconsular] eres el testigo más irrefutable de que he intentado alcanzar el reconocimiento y aprecio de mi educación y de mi cultura, tanto en nuestra provincia, como en Roma, entre tus amigos, hasta el punto de que vosostros tenéis tantas razones para buscar mi amistad, como yo para desear la vuestra.

Depois de breve estadia em Roma, Apuleio retornou ao norte da África no início da década de 150, estabelecendo-se, ao que tudo indica, em Cartago. Em sua terra natal, o autor se notabilizou como orador público e filósofo, pronunciando conferências públicas nas diversas cidades norte-africanas (Harrison, 2000: 5-6). Em Apologia (73, 2), temos um exemplo da atividade de orador público exercida pelo autor, no momento de sua chegada a Oea:

[...] a ruegos de mis amigos doy uma conferencia pública; todos los presentes, que con su grande concurrencia abarrotaban la basílica, en donde tenían lugar las audiciones, entre otras numerosas muestras de aplauso, gritan con voz unánime [...] que me haga ciudadano de Oea.

A estadia de Apuleio em Oea iniciou-se no ano de 157, no decorrer de uma viagem que tinha Alexandria, no Egito, como destino final. No momento em que Apuleio passava por Oea, ele adoeceu e estabeleceu pouso na casa de amigos (Apul., Apol., 72, 1-3). Enquanto se restabelecia da jornada percorrida, Apuleio reencontrou seu antigo companheiro de estudos, Ponciano, "que pocos años antes me había sido presentado en Atenas por algunos amigos comunes y después había estado intimamente vinculado a mí por uma estrecha camaradería" (Apul., Apol., 72, 4).

Interessado em casar sua mãe, a viúva Emília Pudentila, com um distinto marido, Ponciano convenceu Apuleio a permanecer por mais algum tempo em Oea, devendo esperar o próximo inverno para seguir viagem (Apul., Apol., 72, 5). Depois de várias investidas de Ponciano no sentido de estabelecer um matrimônio entre Apuleio e Pudentila, o autor madaurense cedeu e aceitou se casar, renunciando à sua vida errante de orador público (Apul., Apol., 73, 7-8). O casamento, contudo, não foi bem visto por parte da família do primeiro marido da viúva. Emília Pudentila tinha sido anteriormente casada com Sicínio Amico e, 
após a morte deste último, a aliança entre as famílias não se rompera, posto que fora acertado um contrato de futuro casamento - sponsalia - entre a viúva e o irmão de seu falecido esposo, seu cunhado Sicínio Claro (Apul., Apol., 63, 5).

Ao desposar Emília Pudentila, Apuleio acabou atraindo para si a oposição de parte da elite citadina local. Os inimigos do autor em Oea eram principalmente o ex-cunhado de Pudentila, Sicínio Emiliano, e o filho mais novo da viúva, Sicínio Pudente. Foram eles que acusaram formalmente Apuleio - visto como alguém interessado na herança de Pudentila - de utilizar magia amorosa para casar-se com a viúva, fato que o colocaria como réu no tribunal do procônsul da África, em Sabrata, no ano de 159.

Após advogar em causa própria e ser inocentado do crime de magia, Apuleio se estabeleceu na cidade de Cartago, notabilizando-se, no decorrer da década de 160, como escritor, filósofo e orador. A distinção alcançada por Apuleio, em Cartago, é demonstrada pela construção de uma estátua em sua homenagem na cidade. $\mathrm{O}$ autor madaurense afirma, em uma passagem de Florida (XVI, 38): "Qué puede añadirse a tamaño elogio, tributado publicamente por um varón consular [...] [que] ha prometido que está dispuesto a erigirme a sus expensas uma estatua". ${ }^{15}$

As estátuas na Antiguidade possuíam uma evidente função social, servindo como meio de celebração da memória dos mais eminentes indivíduos da comunidade, característica que colocaria em segundo plano, inclusive, o seu caráter estético como obra de arte. ${ }^{16}$ Elas se caracterizariam como peças mnemônicas, resgatando do esquecimento aqueles cuja lembrança, em alguma medida, deveria ser mantida e enaltecida publicamente (Stewart, 2003: 8). De acordo com Apuleio (Apol., 14, 2), "como premio a sus servicios, una ciudad otorga oficialmente a algún personaje la erección de sua propria efigie, para que se contemple em ella [a sua recordação]". O prestígio e a honra associados às estátuas na sociedade romana se relacionariam, por conseguinte, àquilo que Arendt (2001: 14) denomina como busca da imortalidade do homem, dotando suas obras e seus atos de uma permanência eterna.

Tal estátua foi dedicada a Apuleio devido ao fato de ele ocupar "un cargo sacerdotal, [...] y ostentaba la más alta dignidade de Cartago" (Apul., Flor.,

15 A estátua dedicada a Apuleio teria sido uma homenagem decorrente de sua eleição para o cargo de sacerdos Aesculapii em Cartago (Apul., Flor., XVIII, 38; Rives, 1994: 286).

16 O que diferencia as estátuas das esculturas é o fato de que as primeiras têm um caráter social explícito, servindo como veículo de engrandecimento do prestígio de determinados indivíduos, enquanto que as segundas se associam a um valor estético e artístico mais proeminente (Stewart, 2003: 8). 
XVI, 38). O autor madaurense, infelizmente, não oferece nenhuma informação suplementar acerca do tipo de sacerdócio que exerceu na cidade. Agostinho de Hipona (Epist., 138, 19), séculos mais tarde, denominará Apuleio como sacerdos provinciae Africae, isto é, como sacerdote provincial, uma magistratura ocupada por indivíduos ricos e influentes que representavam os seus concidadãos diante do Império, sendo considerada o ápice da carreira política dos mais destacados decuriões locais (Picard, 1954: 168). ${ }^{17}$

A distinção pública concedida a Apuleio em Cartago também pode ser examinada por intermédio dos diversos discursos laudatórios por ele compostos. Tais performances oratórias louvavam a honra, a dignidade e a sabedoria dos indivíduos mais notáveis da cidade, tais como procônsules e membros eminentes da elite local, fato que evidencia a proximidade do autor com personagens de vulto da sociedade norte-africana romana e o seu pertencimento à aristocracia cartaginesa. Concomitantemente a isto, Apuleio aproveitava a oportunidade para igualmente ratificar a sua honra, como um orador consagrado que se colocava no mesmo patamar, em termos de prestígio, em relação aos homenageados por seus discursos.

Vê-se, por exemplo, um excerto do discurso laudatório elaborado em honra do procônsul Severiano Honorino (162/163). Nele, o autor madaurense demonstra publicamente toda a sua erudição como orador versátil e afamado em Cartago. Mais do que homenagear o governador provincial, o que se observa é a elaboração de uma espécie de autoelogio de Apuleio:

[Escrevo] sátiras y enigmas, historias variadas, discursos elogiados por los oradores y diálogos que complacen a los filósofos. Y redacto todas estas obras y otras semejantes, tanto en griego como en latín, con la misma esperanza, igual entusiasmo e idéntico estilo. Ojalá pudera yo, oh excelentíssimo proncónsul, oferecerte todas estas obras mías, no una a uma, [...] y disfrutar de tu laudable testimonio acerca de todas las creaciones de mi musa. Y no porque yo tenga necessidad alguna de renombre, puesto que mi fama, ya antigua, se há mantenido intacta y floreciente (Apul., Flor., IX, 28-31).

Para os anos posteriores à década de 160, não dispomos de nenhuma informação acerca de Apuleio. Uma hipótese para esse período final de sua vida foi formulada por Harrison (2000: 179-180), que, analisando o didatismo das obras filosóficas De Platone e De Mundo, livros considerados, por ele, como posteriores a 170, afirma ter o autor madaurense exercido a atividade de

17 Para uma lista completa dos sacerdotes provinciais da África Proconsular, atestados pelas fontes epigráficas, ver Duncan-Jones (1968). 
professor de retórica e de filosofia, bem como acolhido diversos pupilos sob a sua direção e orientação. ${ }^{18}$ Em suma, Apuleio possivelmente terminou seus dias como grammaticus ou rhetor em Cartago e escreveu as duas obras citadas acima para seus alunos (Harrison, 2000: 179-180).

Tal possibilidade é corroborada por outro dado retirado das duas obras filosóficas de Apuleio. Tanto em De Platone (I, II, 219) quanto em De Mundo (285), o autor dedica os seus escritos a um jovem denominado Faustinus, provavelmente filho de Apuleio com Emília Pudentila. Como em Apologia, discurso proferido em 159, não se menciona o nome de Faustinus como filho de Apuleio; pode-se presumir que tal criança nasceu em Cartago, talvez no começo da década de 160. Considerando que a idade habitual para o início dos estudos filosóficos na escola do grammaticus girava em torno dos 11 ou 12 anos, há razoável certeza da publicação de De Platone e De Mundo, nos primeiros anos da década de 170, e de que Apuleio, em consonância com suas atividades acadêmicas, dedicou a obra a seu filho, possível calouro da escola do grammaticus.

O último indício da biografia de Apuleio foi a confecção da obra Metamorphoses. Na historiografia, há certa obscuridade sobre a data exata de sua produção. ${ }^{19}$ Os autores, contudo, são unânimes em afirmar que as Metamorphoses foram escritas próximo à morte do autor, entre os anos de 170 e 180. Alguns dados possibilitam inferir que as Metamorphoses foram compostas após Apologia e Florida, ou seja, posteriormente à década de 160 . Tal conjetura pode ser averiguada por intermédio da ausência de qualquer referência a uma novela latina nos dois trabalhos citados acima, ${ }^{20}$ uma ausência relevante na medida em que, em ambas as obras, o autor fornece um catálogo de escritos de sua própria autoria (Apul., Apol., 38, 1-2; Apul., Flor., IX, 27-28; XX, 5-6).

Outra evidência sugere a composição das Metamorphoses nos anos finais da década de 170. Chama a atenção um episódio na história da personagem Psique, no qual ela é informada acerca da proibição de oferecer abrigo a escravos fugitivos (Apul., Met., VI, 4-5). Segundo Ulpiano (Digestum, VI, 4; VII, 4; II, 6), tal legislação teria sido decretada no ano de 177, no governo de Marco Aurelio,

18 Contra tal interpretação de Harrison (2000: 179-180), ver Macías Villalobos (2011: 9395), que delimita a composição das obras De Platone e De Mundo como anteriores à década de 150, sendo escritas por Apuleio ainda em Atenas, no período em que este último estudou na escola do rhetor.

${ }^{19}$ Entre os principais autores consultados acerca da cronologia das Metamorphoses de Apuleio, podem-se citar: Gaisser (2008); Harrison (2000); Hanson (1989); Hidalgo de la Vega (1986); Royo (1998); Bradley (2012); Walsh (1995).

20 Podemos conceituar novela latina como um gênero literário que agrupa em torno de um tema central diversas tramas paralelas entrecruzadas e no qual predomina o recurso ao fantástico e ao maravilhoso (Silva, 2001: 27). 
fato que situaria a composição das Metamorphoses entre os anos de 170/180 (Walsh, 1995: 248-251).

No tocante à datação da morte de Apuleio, muito pouco se sabe a respeito. Fora o consenso de que teria ocorrido na cidade de Cartago, vários autores não concordam com uma data unívoca. Julia Haig Gaisser (2008: 1-2) estabelece a morte de Apuleio por volta do ano de 170, data também aceita por José Maria Royo (1998: 15), Santiago Segura Munguía (1980: 16) e Paul Vallette (2002: xii). Já Stephen Harrison (2000: 10), estipula uma data posterior a 180, com a qual Maria José Hidalgo de la Vega (1986: 9-10), Walsh (1995: 248-251) e Vincent Hunink (1997: 5) também concordam. Dessa forma, é prudente estabelecer uma cronologia flexível em relação à morte do autor, em face das poucas evidências disponíveis sobre o assunto. Em consonância com a bibliografia especializada, Apuleio teria falecido entre as décadas de 170 e 180.

\section{Conclusão}

Apuleio, ao longo de sua vida, alcançou grande distinção, ocupando cargos públicos, tendo a honra de ter estátuas erigidas em sua homenagem e possuindo o reconhecimento como um destacado orador e filósofo. Neste contexto, ele deve ser percebido como um seleto integrante da aristocracia romana, um indivíduo cuja excepcional erudição o colocava numa posição de prestígio entre os seus pares. Em termos gerais, a posse da paideia por Apuleio tem que ser observada como um extraordinário instrumento na concorrência por visibilidade e prestígio. Não à toa, de decurião de uma pequena e obscura cidade nos limites do orbis romanorum, Apuleio, por intermédio de sua formação cultural, ascendeu socialmente, colocando-se em patamares afins de cônsules e procônsules, membros destacados da mais importante ordem social romana, a senatorial.

Iniciando os seus estudos na periférica Madaura, na Numídia, e os aperfeiçoando em centros renomados como Cartago, Atenas e Roma, Apuleio seguiu um itinerário comumente utilizado pelos membros das elites citadinas norte-africanas. Exemplos como os de Apuleio podem ser observados nas biografias de diversas personagens locais. Marcus Cornelius Fronto, natural de Cirta, e Salvius Julianus, nascido em Hadrumetum, podem ser citados como destacados conterrâneos e contemporâneos de Apuleio que alcançaram projeção por conta de sua excepcional erudição, ocupando postos de prestígio na administração imperial (Keulen, 2014; Raven, 1993: 124-126). Pode-se também apresentar o exemplo da eminente família dos Aemilii de Oea, cujo investimento em formação educacional, verificado no caso de Ponciano, que estudara filosofia com Apuleio em Atenas, proporcionou-lhes a condição necessária para 
ascender ao ordo senatorius no início da década de 180, fato atestado em inscrições epigráficas que denominam Lucius Aemilius e Aemilius Frontianus como, respectivamente, procônsul da Ásia e sacerdotes domus Augustae Palatinae (I.R.T., 230; C.I.L, VI, 2010).

Além de paradigmático no processo de ascensão social dos norte-africanos no Império, o estudo da biografia de Apuleio também se mostra um instrumento importante no sentido de relativizar interpretações dicotômicas acerca da sociedade romano-africana, que ora valorizam as influências romanas sobre a região, ora enfatizam a importância dos elementos nativos na construção da história local. Nesse sentido, são fundamentais os estudos críticos ao secular conceito de romanização. ${ }^{21}$ Delineou-se, a partir da década de 1990, uma nova compreensão acerca das relações do Império Romano com as populações autóctones norte-africanas, ${ }^{22}$ aproximando-se de uma percepção multifacetada em termos de transformação sociocultural. Citando Revel (2011: 2): “[...] mais do que esperar homogeneidade, necessitamos reconhecer que houve um inerente paradoxo de similaridade e de variabilidade, como parte fundamental da identidade romana".

Corroborando com esta perspectiva, Janet Huskinson (2000a, 2000b) observa a existência, entre os séculos I a.C. e II d.C., de um common ground de elementos compartilhados, em grande medida, pelas diversas elites que compunham o orbis Romanorum. ${ }^{23} \mathrm{O}$ domínio do latim, a posse da cidadania romana, a participação nos cargos públicos, nos cultos e nas festividades cívicas, o gozo das

${ }^{21}$ O termo romanização a princípio, foi utilizado para explicar os contatos entre os romanos e os povos por eles conquistados, dando ênfase ao processo de aculturação das populações autóctones, que assumiam os padrões estéticos, a língua e os valores de seus conquistadores. Pressupunha-se que havia um desnível cultural entre os romanos e os provinciais, uma relação que levaria os pesquisadores a construírem pares dicotômicos como civilizados e primitivos. Tal visão desconsiderava a autonomia dos agentes históricos frente aos processos sociais e culturais dos quais faziam parte, legando às populações conquistadas pelo poderio romano uma posição de passividade frente ao que era considerado culturalmente superior. O conceito de romanização constituía um processo em que o outro se civilizava na medida em que se tornava romano (Mendes, 2007: 38-39).

22 Acerca dos novos vieses referentes à relação entre romanos e as populações provinciais, ver Revell (2011), Hingley (2010) e Mattingly (1996; 2011).

${ }^{23}$ A apropriação desse common ground romano não se limitou, obviamente, às elites locais. Pensando-se, como Ginzburg (2006), no conceito de circularidade cultural como formas de inter-relação culturais entre diferentes estratos sociais, percebe-se a existência de diversas situações cotidianas em que essa "cultura de elite" poderia ser disseminada e assimilada pelos humiliores, como no caso dos eventos realizados nos teatros, anfiteatros, basílicas e circos, abertos a um público muito mais amplo do que somente o ordo decurionum local. 
benesses urbanas nos teatros, anfiteatros e termas e a difusão de uma educação baseada na paideia eram elementos comuns que davam significado àquilo que poderia ser denominado como "romano". Tal concepção, não invalidaria, para Huskinson (2000a: 121), a dinâmica multifacetada das sociedades provinciais, uma vez que esse common ground era diversamente adotado, experimentado e assimilado nas diferentes regiões do Império. Em resumo e se apropriando das percepções de Mattingly (2011: 236-245), pode-se dizer que as diversas etnias submetidas ao domínio romano ressignificavam, de acordo com seus interesses e com suas próprias tradições, os elementos comuns da "romanidade", percebendo-se como romanos, ao mesmo tempo que mantinham os vínculos identitários com sua cultura ancestral.

Levando-se em conta tais percepções delineadas por Revel (2011), Huskinson (2000) e Mattingly (2011), pode-se compreender a própria declaração de Apuleio acerca de sua terra natal e de suas origens, afirmação que consideramos fulcral no sentido de melhor endentermos o significado da identidade romana no norte da África:

En cuanto a mi patria, habéis dicho, basándoos en mis proprios escritos, que está situada en la frontera misma de Numidia y Getulia. Em efecto, yo mismo declare, en uma conferencia pública, [...] que yo era seminúmida y semigétulo. No veo por qué razón he de avergonzarme más de ello que Ciro el Antiguo ${ }^{24}$ por haber nacido de raza mestiza [...], pues no se ha de tener em cuenta en donde há nacido uma persona, sino qué formación moral tiene. [...] Y no he dicho esto, porque me averguence de mi patria, cosa que jamás haría yo, aunque fuéramos aún la ciudadela del rey Sifax. ${ }^{25}$ Pero, uma vez vencido éste, pasamos a ser súbditos del rey Masinisa, ${ }^{26}$ por concesión graciosa del Pueblo romano, y después, tras una nueva fundación, [...] nos hemos convertido en um colonia muy floreciente. En esta colonia mi padre padre ocupó el elevado cargao de duúnviro [...] y yo ocupo su mismo puesto en esa querida cuidad desde que comencé a formar parte de sua cúria, manteniéndo-me a la altura de tal cargo (Apul., Apol., 24, 1-10).

${ }^{24}$ Ciro foi o maior dos reis persas da Antiguidade, sendo semimedo, por sua mãe Mandane, e semipersa, por seu pai Cambisés (Munguía, 1980: 95).

${ }^{25}$ Sifax foi um rei númida que teve importante papel na Segunda Guerra Púnica, sendo derrotado pelas tropas romanas e transportado a Roma para o desfile triunfal de Cipião Africano (Raven, 1993: 45).

${ }^{26}$ Massinisa, rival de Sifax, colaborou com Cipião Africano na luta contra os cartagineses. Depois da vitória romana em Zama, recebeu a soberania sobre as terras da Numídia (Munguía, 1980: 96). 
O que se pode concluir da passagem acima é que Apuleio se percebia como um indivíduo híbrido, meio romano, meio gétulo/númida. A mestiçagem inerente à sua identidade em nada atrapalhava ou contradizia a sua posição como cidadão romano, haja vista a participação política na cúria de Madaura, à época uma colônia romana, fato que a colocava como uma extensão territorial da própria Roma. Apuleio, por conseguinte, identificava-se tanto como africano - o que fica claro no momento em que o autor se filia a grupos autóctones e rememora o passado númida de sua terra natal - quanto como romano, na medida em que possuía a formação educacional baseada na paideia, elemento de distinção e de identificação da elite romana, componente indispensável para a obtenção de uma posição de destaque na sociedade imperial. ${ }^{27}$

\section{REFERÊNCIAS BIBLIOGRÁFICAS}

\section{Documentação primária impressa}

AGOSTINHO. A cidade de Deus. Tradução de Oscar Paes Lemes. Rio de Janeiro: Vozes, 2002.

APULEIO. O asno de ouro. Tradução e notas de Francisco Antonio de Campos. Lisboa: Europa-América, 1990.

APULEIO. Sobre o deus de Sócrates. Tradução de Rosângela Maria Souza Silva. São Paulo: USP, Dissertação de Mestrado, 2001.

APULEYO. Apología y Flórida. Introducción, traducciones y notas de Santiago Segura Munguía. Madrid: Gredos, 1980.

APULEYO. Obra filosófica. Introducción, traducciones y notas de Cristóbal Macías Villalobos. Madrid: Gredos, 2011.

AUGUSTINE. The letters of St. Augustine. Translated by J. Sparrow Simpson. New York: The Macmillan Company, 1919.

27 Como observado por Bradley (2012 $: 145-146)$, Madaura, cidade natal de Apuleio, era uma civitas influenciada pelas culturas púnica e líbica. Pode-se perceber, por intermédio das inscrições epigráficas provenientes de Madaura, nomes como L. Julius Zabo, Manilius Aris e Mizguar, filho de Baric (I.L.ALG., 2547; 2601; 2624). Na família Apuleii, por exemplo, há um indivíduo denominado C. Apuleius Rogatus, nome que corrobora uma possível ascendência romano-púnica de próprio Apuleio (I.L.ALG., 2276; 2277). 
JUSTINIANO. El digesto de Justiniano. Tomo I, II, III. Traducción de A. D’Ors. Pamplona: Aranzadi, 1972.

\section{Documentação arqueológica}

CORPUS INSCRIPTIONUM LATINARUM: vol. VIII/ vol. VI. Berlin: Academy of Sciences and Humanities, 1881.

INSCRIPTIONS OF ROMAN TRIPOLITANIA. Rome: British School at Rome, 1952.

INSCRIPTIONS LATINES DE L'ALGERIE. Paris: Librairie ancienne honoré champion, 1922.

RECHERCHES ARCHEOLOGIQUES EN ALGERIE. Paris: Ernest Leroux Editeur, 1893.

\section{Obras de apoio}

ALFÖLDY, G. Historia social de Roma. Madri: Alianza Editorial, 1996.

ARENDT, H. Entre o passado e o futuro. São Paulo: Perspectiva, 2001.

BRADLEY, K. Apuleius and Antonine Rome: historial essays. Toronto: University of Toronto Press, 2012.

BUSTAMANTE, R. M. da C.; DAVIDSON, J.; MENDES, N. M. A experiência imperialista romana: teorias e práticas. Tempo, Niterói, v. 9, n. 18, p. 17-41, 2005.

CERTEAU, M. de. A escrita da história. Rio de Janeiro: Forense Universitária, 1982.

CHARTIER, R. A história hoje: dúvidas, desafios, propostas. Estudos históricos, Rio de Janeiro, v. 7, n. 13, p. 97-113, 1994a.

CHAUSA, A. Modelos de reservas de indígenas en el África romana. Gerión, Madrid, n. 2, p. 95-101, 1994.

COARELLI, F. Apuleio a Ostia? D'Arch, n. 6, p. 27-42, 1989.

D'ENCARNAÇÃO, J. Epigrafia: as pedras que falam. Coimbra: Imprensa da Universidade de Coimbra, 2010. 
DUNCAN-JONES, R. P. The chronology of the priesthood of Africa Proconsularis under the principate. EpigStud, n. 5, p. 151-158, 1968.

em 1990).

GAISSER, J. H. The fortunes of Apuleius and the Golden ass. New York: Princeton University Press, 2008.

GUEY, J. Au theater de Leptis Magna. Le proconsulat de Lollianus Avitus et la date de l'Apologie d'Apulée. Revue des Études latines, n. 29, p. 307-317, 1951.

HANSON, J. A. Introduction. In: APULEIUS. Metamorphoses: books I-VI. London: Loeb Classical Library, 1989, p. ix-xiv.

HARRISON, S. J. Apuleius: a latin sophist. New York: Oxford University Press, 2000.

HIDALGO DE LA VEGA, M. J. Sociedad e ideología en el império romano: Apuleyo de Madaura. Salamanca: Ediciones Universidad de Salamanca, 1986.

HUNINK, V. Introduction. In: APULEIUS. Pro se de magia. Amsterdam: Gieben, 1997, p 1-22.

HUSKINSON, J. Elite culture and the identity of empire. In: (Org.) Experiencing Rome: culture, identity and power in the roman empire. New York: Routledge, 2000a, p. 95-124.

HUSKINSON, J. Looking for culture, identity and power. In: Experiencing Rome: culture, identity and power in the roman empire. New York: Routledge, 2000b, p. 3-28.

KEULEN, W. Fronto and Apuleius: two African careers in the Roman Empire. In: LEE, B. T.; FINKELPEARL, E.; GRAVERINI, L. Apuleius and Africa. New York: Routledge, 2014, p. 129-153.

LORIGA, S. O pequeno $x$ : da biografia à história. Belo Horizonte: Autêntica, 2011. 